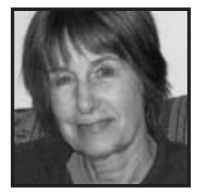

\title{
Commentary: \\ Inquiry: Doing What Comes Naturally
}

\section{Karen Gallas}

\section{ABSTRACT}

We are all born with basic habits of mind that enable us to successfully learn about and master our world. Gradually, however, those abilities are sidelined as children progress through school. Inquiry becomes confused with research, and the agency of children as inquirers is lost. This exploration of the meaning of inquiry identifies three elements that are crucial to the process. Choice, curiosity and gut instinct-hardly fodder for educational research or the standardization of curricula-are presented as central to maintaining healthy lifelong learning.

Suddenly a White Rabbit with pink eyes ran close by her. There was nothing so very remarkable in that; nor did Alice think it so very much out of the way to hear the Rabbit say to itself, "Oh dear! Oh dear! I shall be late!" (when she thought it over afterwards, it occurred to her that she ought to have wondered at this, but at the time it all seemed quite natural); but when the Rabbit actually took a watch out of its waistcoat-pocket, and looked at it, and then hurried on, Alice started to her feet, for it flashed across her mind that she had never before seen a rabbit with either a waistcoat-pocket, or a watch to take out of it, and burning with curiosity, she ran across the field after it, and fortunately was just in time to see it pop down a large rabbithole under the hedge. In another moment down went Alice after it, never once considering how in the world she was to get out again. (Carroll, 1865/2006, pp. 1-2)

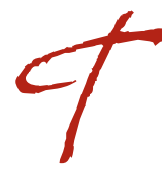

hus began Alice's adventures. And here, I begin a brief exploration of the meaning of inquiry. It seems important, first, to recall what was happening before Alice dove down the rabbit hole. She was sitting by the 
riverbank with her sister, doing what she was expected to do, but with little enthusiasm. Suddenly, the rabbit appeared. Surprisingly, Alice did not take notice of the fact that a rabbit ran past talking to itself. Rather, her split-second decision to follow was based on the flash of the pocket watch which triggered her curiosity and caused her to abandon both her sister and the outward reality of her daily life. In that moment, human nature triumphed over Alice's very British conditioning.

Alice's jump into uncertainty highlights what I consider to be key elements of healthy inquiry. First, there is the element of choice: Alice determines what she will pursue. Second, her curiosity compels her to follow an uncertain path. Third, she is going on her gut instinct that there is something important to be learned, although she is not at all aware of what that might be. Choice, curiosity, gut instinct; we will return to these throughout this discussion.

We humans are born with a deep desire to explore and understand our world. Our early efforts, if we have a healthy family, are encouraged and supported. We reach for objects; they are put closer to our hands. We grab the fur of the family dog and pull; larger hands come in and guide the pressure of our touch. We initiate learning opportunities; our caretakers support our learning. Inquiry is the vehicle through which we begin to adapt to our world and develop the physical, mental and psychic abilities necessary for survival.

Then we reach school age, and for most of us our natural gift for inquiry is shunted aside to be replaced by the belief that real inquiry is something children do not know how to do. Questions, timetables, protocols for inquiry are outlined by adults who have been given the responsibility for, and the power over, our educational journey. (Notice here, I did not say, "by our teachers." If we look at the domino effect in education-how decisions made at the policy level factor down into control over classroom practice, it is much clearer that the adults who design standards and legislate policy, the adults in the academy who study and theorize what I believe are natural abilities, do the shunting aside. As the white rabbit would say, "Oh dear, oh dear.") In the process of codifying the educational process, "inquiry" in schools most often loses the three qualities critical to growth and development that Alice helped us identify. The helping and guiding hand of the caring adult is replaced by the absolutism of standards and prescribed curricula. Choice, curiosity, and gut instinct are sidelined.

The reality of the modern era is that those three descriptors, when referring to children, often evoke fear and concern in adults. (In the United States, at least. I am 
not able to generalize about Canada.) Many parents struggle to find a balance between their concerns about safety, and their desire to foster their children's natural curiosity and creativity in order to develop all of their potential. We want our children to feel they have choices in their lives, but we'd like to determine those choices. We love and celebrate their curiosity, but only if it is exercised in a safe way, that is, under conditions that we deem to be safe. We do not so much like the actions that emanate from gut instinct because we cannot anticipate the circumstances and timing under which they will occur. What is most noticeable here for the adults involved is the issue of control. We want to control our children's experiences so they can be safe, and, in the case of schools, productive. Our behavior comes from love, caring and fear, but also from mislabeling what children are doing. Adult conservatism in this regard reflects a pervasive societal value that children have bad judgment and can't possibly know what's good for them. In this paper, I want to briefly suggest that we misjudge, and thereby mis-serve the development of our children, and ourselves.

My three-year-old grandson, L., has been inquiring into the physics of momentum and the mechanics of wheels and axles for two years. Here are a few examples of how that process has looked:

\section{May 10 - 27 months: The Slide}

L. spends much of his outdoor playtime climbing the slide itself rather than using the ladder or being lifted up to the top of the slide by an adult. At first, his mother and I make sure he gets safely up the slippery surface by holding his hands and helping him climb. He slides down, then turns and tries to scramble on all fours up the slide, without success, repeating this over and over. We continue to help him get back up the slide, holding his hands as he walks upright back up the slide, jumping to catch him if he starts to slip.

In the afternoon, when we return from the beach, we help L. take off his shoes to get the sand out, then turn our attention to unpacking the car. When we finish, we find him standing with evident pride at the top of the slide, barefoot, waiting for us to notice. He spends much of the next hour running up the slide, then sliding back down on his stomach, on his back, on his bottom. He tries going up slowly holding onto the side of the slide with both hands. He tries climbing without holding on, then realizes that a combination of speed of takeoff and grappling with his hands is most effective. He has also decided, when shoes are re-offered to him, that shoes do not help. 
Note in this observation how L.'s actions represent inquiry into the properties of surfaces as well as how to move an object (his body) up a ramp. What are the variables he was considering? Speed/velocity, hands only, feet only, tensile outcomes of shoes versus none, traction. Were we afraid that he would fall and hurt himself? Yes. Did he? No. Choice, curiosity, and gut instinct. He exercised them all. We gained a little bit of courage.

\section{July 1 \& 2 - 28 months: The Wagon}

L. spends the long weekend trying to master the red wagon. The first day he struggles to pull the wagon around obstacles in the garden (chairs, bench). Occasionally, he walks back and forth around the wagon, squatting down to examine the axle and the wheels as he tries to figure out how to make the wagon turn sharply. At one point he is wedged in between two Adirondack chairs and a bench. He pushes the wagon back a bit, picks up the handle, pushes it right to the edge of the garden where the hill drops off sharply, (we gasp!), straightens the wagon out and extricates himself.

The next day, I am pulling the wagon with him. He says, "L. wants to park the wagon on the hill" (a small mound around the oak tree). He tries unsuccessfully to pull the wagon up and have it stay at the top. Finally, I ask him if he wants help. He says, "yes." So I pull the wagon up to the top of the mound and rest the handle against the tree trunk. We are satisfied and walk away. A bit later, he is back outside trying again to pull the wagon up and over the mound. I watch as he becomes frustrated. He squats down, scrutinizes the wheels and the axle, stands up and tries to turn the handle to pull it, but seems to lack the strength. He leaves the wagon and returns to the house. Ten minutes later, after a drink of orange juice, he heads back to the wagon, pulls it down onto the lawn, backs it up, then, turning sharply, he pulls it as fast as he is able toward the mound. This time he gets the momentum he needs to achieve the top. I clap. He smiles very briefly, then turns the wagon around, pulls it down the little hill and around the garden.

Sunday, late afternoon: L., barefoot, has the wagon at the front of the house and is pulling it along the flagstone path. I am sitting on the steps by the door, watching. He is very absorbed in pulling the wagon to the end of the path, backing it up, turning it in a very small space, then pulling it back the other direction. He repeats the entire sequence several times. Finally, he gets stuck in the perennial garden that borders the path. One wheel has dropped onto uneven ground and is threatening to pull the wagon into the flowers. L. sees the dilemma and tries, unsuccessfully, to turn the 
wagon so it comes out. He stops, puts down the handle, walks around the other side of the wagon and squats down to get a better look. He stands up, picks up the handle and tries turning the axle the other way without good results. He repeats this procedure of stopping, squatting, looking. He stands up and makes a smaller different turn; the wagon starts to roll quickly and rolls over his bare foot. He stops suddenly, obviously in pain, but doesn't cry, puts down the handle, walks over to the stone steps opposite me, sits down on the bottom step, puts his head in his hands and leans his elbows on his knees for several seconds. Then he looks up at me. I say, "That hurt, huh?" He nods slightly, stands up and runs pell-mell around the side of the house toward the porch where he knows his mother is sitting. He arrives there, then begins to cry. Priceless.

Choice, curiosity, and courage. Also, knowing where to go for sympathy if those traits result in pain and suffering.

Although I could continue this narrative with detailed notes on how L. has continued to explore the work of axles, wheels, momentum, balance, I will only summarize by reporting that he has recently explored how far the body can tilt off a stable object before it falls, how much momentum one needs in order to leap successfully onto a stable object using one leg only as the catapult, how wheels and dials turn and the resulting actions that occur in electrical devices. When I describe his inquiries in this way, it is obvious to me that they are about physics. They are scientific inquiries. However, when his mother and father observe them, their gut response focuses on his safety, or lack thereof. They put their fear, based on a long history of reading about tragic accidents that occur in homes, onto the template of his actions. Yet his actions are inherently neutral; they are not value laden. He is just trying to exercise (yes, you know what's coming) choice, curiosity, and gut instinct in the pursuit of his own growth and learning.

Oh, you might say, there is a limit to how long children should be allowed to exercise those choices. At some point, adults must intervene to push them towards the full achievement of their potential. Perhaps, perhaps. But let me just throw in a tangent that may seem off topic, but allows me to indirectly bolster my argument. Consider eating: the process of taking food into our bodies.

Our children's food intake has increasingly become a focus of concern for health care professionals, teachers, and parents. Childhood obesity and diabetes are on the rise. Eating disorders are serious health concerns. Too much eating; too little eating; or, too much eating and purging. Our solutions focus on prevention: healthier 
choices, more exercise. But what does healthy eating in young children actually look like? From birth, children know when they are hungry and when they are full. They also know what they want to eat. Essentially, they graze.

Most parents believe that it is their job to help their child eat a balanced diet. So, when the child begins to eat solid food, parents are the deciders. They determine what should be eaten and how much. Often, "how much" is too much. What, you may ask, is my point? This is a commentary on inquiry, not eating. However, for young children food is one of their first areas of inquiry. Left to their own devices with a healthy array of choices, they will graze their way through a balanced diet. I would describe L.'s forays into my vegetable garden in great detail if space allowed because it would be yet another description of inquiry in action. Briefly, he roams the garden like a wild turkey: a taste of red currants, a few blueberries, some dill and basil, seven cherry tomatoes, parsley as a chaser. Now, mom, could I have a snack of cheese and crackers... You get the drift.

My next two examples of inquiry will certainly appear benign in comparison with a two year old hurtling through space, but I want to extend this discussion to the lives of teachers. Choice, curiosity, and gut instinct look different there, but they are still asking to be recognized. In September of 1989, before I became involved in classroom research, I decided to write a daily account of the life in my first grade classroom (Gallas, 1988). I knew it was a crazy idea, given the tremendous amount of energy and time I devoted each day to provisioning my classroom, planning for teaching, and the teaching itself, but I just had to do it. What I experienced every day with my students was astonishing, but I had no way to hold onto the days. There were so many things I wondered about, so I decided to write. Essentially I began a yearlong inquiry into the life of my classroom.

Every day I would return from school, sit down at my computer, write for an hour, fix dinner for my children, talk a bit with my husband, get the children to bed, and resume writing. Sometimes I would wake in the middle of the night and write. The teaching brought me joy and constant surprises; the writing enabled me to process the days. By the end of the year I had written hundreds of pages. The following September, I saw a notice inviting teachers to join the Brookline Teacher Research Seminar, which was just forming. I joined. From that point on, my inquiry evolved into a formal practice of teacher research.

I raise this example so that we can move into a consideration of how inquiry looks for teachers in the classroom and to briefly raise the distinction between 
inquiry and research. For many educators, the words inquiry and research are used interchangeably. For example, consider this definition of inquiry from the International Reading Association website:

The process of inquiry begins with a genuine question, that is, a question that motivates the questioner to persist in seeking the answers. Authentic questions are rarely well formulated or structured at the outset. Rather, structure emerges through the process of inquiry. Inquiry is not merely a matter of asking and answering questions. It is a way of engaging the world and other people. Communication and social relationships play an important role in inquiry as questioners seek the advice and expertise of peers and more knowledgeable others, share their findings, reflect upon the results of the inquiry, and take up new questions that arise. (Inquiry section)

Here, the question is highlighted as the beginning point, and the process, as described, is a research process: question, systematic methodology, literature search, reporting, new questions. This definition illustrates how inquiry is often lumped into the same clay as research. I propose that it is not, really, a true description.

Inquiry [enquire]: Middle English enquere (later inquere), from Old French enquerre, from a variant of Latin inquirere, based on quaerere 'seek'. (Oxford English Dictionary)

Inquiry, in its original usage, is defined as a seeking. What are we seeking? We are seeking to understand our particular "small-ly" defined universe for the purposes of our growth, our development, and maybe even to find truth. As such, we conduct an inquiry. We can't conduct a question. There is no set time frame; inquiries are notorious for spiraling from weeks into years. We aren't always sure what we're trying to find out or achieve. Our methods aren't formalized and structured; our questions often remain unarticulated. Inquiry is a process of seeking. I conducted an inquiry through the writing process. Artists carry out inquiries through media. Actors use performance; dancers work through movement. Children play.

Although my yearlong inquiry into the life of my classroom did eventually lead me into the field of research, that is not necessarily the goal of teacher inquiry. Research is an avocation that suits some people in some circumstances. Inquiry is a process of learning that is essential to our complete development as human beings. It is highly individual; we can't predict which rabbit hole we will want to dive down, although, if we are fortunate enough to be able to find the correct series of rabbit holes for ourselves, our lives are hugely enriched and we find the life work we are 
superbly fitted to do. But how many of us and how many of the children in our schools truly have the opportunity to dive down those rabbit holes based on the exercise of our choice, curiosity, and gut instincts? And what if each of us could go down, say, one rabbit hole a year? How would the world be different? What if we stepped out of what other people tell us we should be curious about, sat down for a short spell by the riverbank, or the side of our classroom, and simply opened ourselves to the possibility that the rabbit dressed in the waistcoat might run by? What would be gained for us and our students? What would be lost?

"One thing flows into another and cannot be grasped. Before the rain stops we hear a bird. Even under the heavy snow we see snowdrops and some new growth" (Suzuki, 2006, p. 138).

\section{References}

Carroll, L. (2006). Alice's adventures in wonderland. United States: ReadHowYouWant. (Original work published 1865)

Gallas, K. (1988). Diary of an American classroom, unpublished manuscript.

International Reading Association. "Standards for the Assessment of Reading and Writing," Retrieved April 29, 2011, from http://www.reading.org/General/Current
Research/Standards/AssessmentStandard s/Assessment_standards_Glossary.aspx

Oxford English Dictionary. Definition of "enquire." Retrieved April 29, 2011, from http://oxforddictionaries.com/definition/ enquire

Suzuki, S. (2006). Zen mind, beginner's mind. Boston: Shambala Publications, Inc.

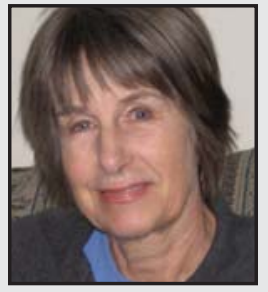

Karen Gallas taught for more than thirty years in urban, suburban and rural public schools as an early childhood and elementary teacher. Her publications include numerous articles and four books, The Languages of Learning, Talking Their Way into Science, 'Sometimes I can be Anything': Power, Gender and Identity in a Primary Classroom, and Imagination and Literacy. Her involvement in education continues through consulting with schools, colleges and universities, museums and teacher research groups. She also works with children and adults as a psychotherapist and a yoga teacher. 